\title{
PRODUTIVIDADE DE RAÍZES DE MANDIOCA CONSORCIADA COM MILHO E CAUPI EM SISTEMA ORGÂNICO (1)
}

\author{
ANTONIO CARLOS PRIES DEVIDE $\left({ }^{2 *}\right)$; RAUL DE LUCENA DUARTE RIBEIRO $\left({ }^{3}\right)$; TERESA LOSADA VALLE $\left({ }^{4}\right)$; \\ DEJAIR LOPES DE ALMEIDA $\left({ }^{5}\right)$; CRISTINA MARIA DE CASTRO $\left({ }^{2}\right)$; JOSÉ CARLOS FELTRAN $\left({ }^{4}\right)$
}

\begin{abstract}
RESUMO
Foram avaliados sistemas orgânicos de produção de mandioca "de mesa", em Seropédica (RJ). O experimento constou dos seguintes tratamentos: monocultivo de mandioca (cv. IAC 576-70) e consórcios com milho experimental (cv. Eldorado), caupi (cv. Mauá) e milho+caupi. O manejo orgânico foi padronizado e toda a área experimental irrigada durante o período de permanência do milho no sistema. Do milho, foram colhidas espigas verdes (imaturas) e a parte aérea acamada na superfície do solo. O caupi foi incluído como adubo verde e cortado na floração, sendo mantidos os resíduos na superfície do solo. Ambos os consortes ocuparam as entrelinhas da mandioca, de modo alternado, semeados após a primeira capina da cultura principal. A cultivar IAC 576-70 mostrou-se adaptada ao manejo orgânico, com produtividade de raízes de padrão comercial próxima a $31 \mathrm{Mg} \mathrm{ha}^{-1}$. Não houve diferenças significativas entre o monocultivo e os três tipos de consórcios testados. A inclusão do milho representou potencial de renda adicional ao produtor, colhendo-se, em média, 18.125 espigas ha-1, o que correspondeu a 5,1 $\mathrm{Mg} \mathrm{ha}^{-1}$. Os resíduos provenientes da roçada do caupi proporcionaram um aporte de biomassa fresca de $12 \mathrm{Mg} \mathrm{ha}^{-1}$, com uma expressiva contribuição em nitrogênio (cerca de $44 \mathrm{~kg}_{\text {de }} \mathrm{N} \mathrm{ha}^{-1}$ ). A fabácea (leguminosa) cobriu por completo as entrelinhas da mandioca, demonstrando seu potencial de controle à erosão e a ervas espontâneas. O consórcio triplo mostrou-se vantajoso tendo em vista que a receita obtida com a venda do milho verde justificaria os custos da irrigação, além dos benefícios da inclusão do caupi e da não interferência dos consortes na produtividade da mandioca.
\end{abstract}

Palavras-chave: Manihot esculenta, consórcio, adubação verde, agricultura orgânica.

\section{ABSTRACT \\ YIELD OF CASSAVA ROOTS INTERCROPPED WITH CORN AND COWPEA IN AN ORGANIC SYSTEM}

Organic systems were evaluated for cassava root production directed to human comsumption in natura, at Seropédica-RJ. Treatments consisted of: cassava ('IAC 576-70') in single cropping and its intercropping with corn ('Eldorado'), cowpea ('Mauá') or corn plus cowpea. The organic management was standardized and the experimental area was submitted to artificial irrigation during the period of stay of maize in the system. "Green" (immature) corn ears were harvested at the "point" required for fresh marketing and the shoot placed on the ground. The cowpea was included to function as green manure being cut at flowering with residues left on the soil surface. Corn and cowpea were sown between cassava rows, in an alternate design, following the first weeding of the main crop (cassava). The cultivar IAC 576-70 showed suitability with respect to organic management, yielding approximatelu $31 \mathrm{Mg} \mathrm{ha}^{-1}$ of marketable roots. No significant differences were detected between cassava single cropping and any of the intercropping tested systems. Thus, corn crop has considerable potential for additional income to the growers. Yield of 'Eldorado' corn averaged 18.125 ears ha $^{-1}$ correspponding to $5,1 \mathrm{Mg} \mathrm{ha}^{-1}$. Residues coming from cowpea cutting brought about an input close to $12 \mathrm{Mg} \mathrm{ha}^{-1}$, which meant an expressive contribution in nutrient elements, especially nitrogen (about $44 \mathrm{~kg} \mathrm{~N} \mathrm{ha}^{-1}$ ). The legume crop, in addition, completely covered cassava inter-rows demonstrating its potential for controlling erosion and weeds. The triple intercropping becomes advantageous considering that corn harvesting would justify irrigation and that inclusion of cowpea meant benefitial effects to the system and did not interfere on cassava yield.

Key words: Manihot esculenta, intercrop, green manure, organic agriculture.

( $\left.{ }^{1}\right)$ Recebido para publicação em 6 de dezembro de 2006 d aceito em 5 de agosto de 2008.

$\left({ }^{2}\right)$ Pólo Regional do Vale do Paraíba/APTA/SAA, Caixa Postal 032, 12400-970 Pindamonhangaba (SP) antoniodevide@apta.sp.gov.br ${ }^{*}$ ) Autor correspondente; cristinacastro@apta.sp.gov.br

$\left({ }^{3}\right)$ Departamento de Fitotecnia/Universidade Federal Rural do Rio de Janeiro, 23851-970 Seropédica (RJ). E-mail: lucena@ufrrj.br;

$\left({ }^{4}\right)$ Centro de Grãos e Fibras, IAC, Caixa Postal 28, 13012-970 Campinas (SP). E-mail: teresalv@iac.sp.gov.br; feltran@iac.sp.gov.br.

$\left({ }^{5}\right)$ Centro Nacional de Pesquisa de Agrobiologia - Embrapa Agrobiologia, 23890-000 Seropédica (RJ) dejair@cnpab.embrapa.br. 


\section{INTRODUÇÃO}

A mandioca (Manihot esculenta Crantz) é uma espécie nativa do Brasil e está distribuída em todo o território nacional (VALLE, 2005). A lavoura emprega cerca de dois milhões de pessoas considerando toda a cadeia produtiva. A agricultura familiar é responsável por $84 \%$ da produção de mandioca no País (MDA, 2005) e o consumo per capita de raízes (51 $\mathrm{kg} \mathrm{hab}^{-1} \mathrm{ano}^{-1}$ ) supera a média mundial de $17 \mathrm{~kg} \mathrm{hab}^{-1}$ $\mathrm{ano}^{-1}$ (FAO, 2005).

Na cultura da mandioca, os produtores familiares praticam sistemas agrícolas variados e sem critérios técnicos definidos, frequentemente com baixa produtividade $\left[13,8 \mathrm{Mg}^{-1}\right.$ média anual em 2002, IвGE (2005)]. Na perspectiva de melhor utilizar os recursos disponíveis, empregam grande número de genótipos locais, com produtividade variável, predominantemente em áreas cujos solos possuem baixo teor de fósforo assimilável (LoRENZI, 2003).

O cultivo de mandioca no Estado do Rio de Janeiro é uma atividade ligada a pequenos e médios agricultores, com produtividade média de $16,0 \mathrm{Mg} \mathrm{ha}^{-1}$, sendo destinada à alimentação humana in natura ou comercializada nas formas de farinha e polvilho (ANDRADE et al., 1999). Na Região Metropolitana, com destaque para o município de Seropédica, concentrase a produção de mandioca "de mesa" em monocultura e com intenso preparo do solo, uso de herbicidas e outros agrotóxicos. O clima caracterizase por períodos de elevada precipitação pluvial, entre outubro e março, com chuvas esporádicas no inverno, e um 'veranico' em janeiro/fevereiro, caracterizando a necessidade de irrigação para outras culturas, como a do milho. O excessivo revolvimento da camada superficial do solo para o plantio da mandioca, predominantemente em setembro-outubro, associado ao lento crescimento inicial e alta intensidade de chuvas, têm contribuído para a erosão e a degradação da fertilidade natural nas áreas cultivadas.

O estabelecimento de consórcios simultâneos com culturas de valor econômico e também com adubos verdes, visa, além de renda adicional, melhor cobertura do solo, aporte de nutrientes e matéria orgânica, distribuição da força de trabalho e manutenção do equilíbrio biológico no agroecossistema. A escolha do caupi deve-se à maior velocidade de cobertura do solo (Alvarenga et al., 1995). Sob o ponto de vista de controle à erosão, este fato é significante, sobretudo por ser a mandioca frequentemente cultivada em locais declivosos, como ocorre em diversas regiões do Estado do Rio de Janeiro.

Por ser considerada rústica, em comparação a muitas outras espécies, a produção orgânica de mandioca pode aumentar o número de adeptos desse modelo de cultivo e conferir maior segurança àqueles que pretendem converter suas unidades produtivas. Entretanto, há carência de resultados científicos sobre seu cultivo orgânico e consorciada com milho para fins de colheita de espigas verdes ou com caupi para adubação verde. Em Paranavaí (PR), foram registrados 1.000 hectares convertidos ao sistema orgânico, nos quais a mandioca vem sendo consorciada com soja, feijão e girassol (BEZERRA, 2004).

A hipótese testada foi de que as culturas consortes não prejudicam a produtividade de mandioca no manejo orgânico irrigado. Foram avaliados os resultados produtivos do consórcio entre a mandioca, o milho e o caupi, visando à colheita de raízes para o consumo in natura, de espigas "verdes" e o aporte de biomassa e nutrientes pelo caupi ao solo.

\section{MATERIAL E MÉTODOS}

O experimento foi instalado no município de Seropédica, Região Metropolitana do Estado do Rio de Janeiro, a $22^{\circ} 45^{\prime} \mathrm{S}, 43^{\circ} 42^{\prime} \mathrm{W}$ e altitude de $33 \mathrm{~m}$, no SIPA (Sistema Integrado de Produção Agroecológica) - "Fazendinha Agroecológica km 47" (Almeida et al., 2003). O clima é do tipo 'Afw' tropical, segundo a classificação de Köppen, com inverno seco. As respectivas médias de precipitação pluvial e a temperatura dos últimos 30 anos na região são, respectivamente, de $1.200 \mathrm{~mm}$ e $28^{\circ} \mathrm{C}$ (InMet/PesagroRIo, 2005). Os valores no período do experimento são apresentados na Figura 1.

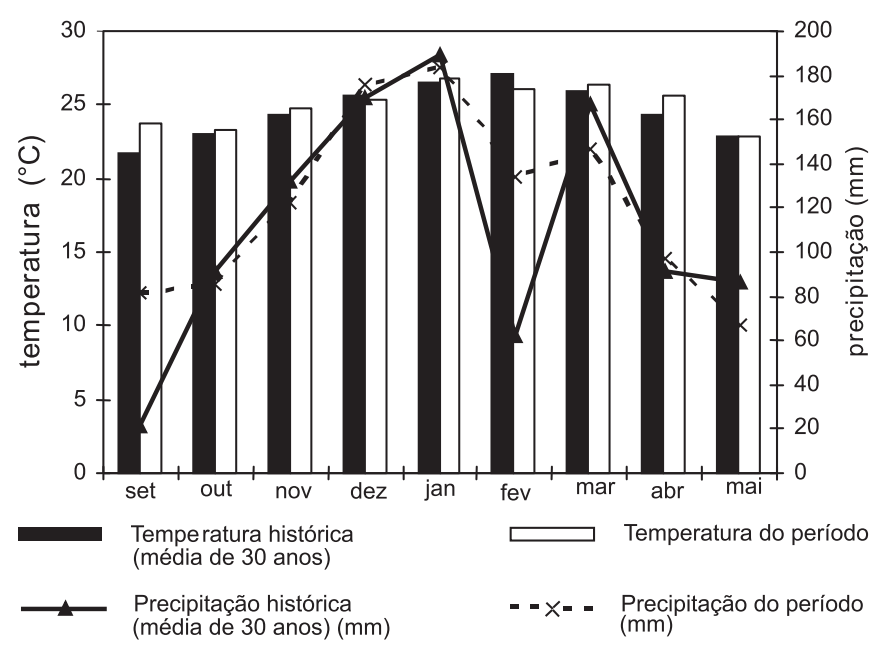

Figura 1. Médias históricas de temperatura e precipitação pluvial em Seropédica (RJ) e no período de setembro de 2004 a maio de 2005 (INMET/PESAGRO-RIO, 2005). 
O solo, classificado como Argissolo VermelhoAmarelo, horizonte A moderado, textura argilosa, topografia plana e boa fertilidade (Tabela 1) teve seu preparo mecanizado com uma aração a $20 \mathrm{~cm}$ de profundidade, seguida de gradagem.

Foi utilizada a cultivar de mandioca de mesa IAC 576-70, de excelente desempenho agrícola e qualidade culinária, a mais cultivada no Estado de São Paulo para comercialização nos mercados hortícolas, indústrias de congelados, com expressiva área na agricultura periurbana (LORENZI e VALLE, 2002) e recém-introduzida no Estado do Rio de Janeiro. Para o milho (Zea mays) empregou-se a cv. Eldorado, de dupla aptidão - espigas verdes e grãos secos considerada eficiente no uso do nitrogênio (MACHADO, 1998). Para adubação verde utilizou-se o caupi (Vigna unguiculata) cv. Mauá, de crescimento indeterminado, que também pode ser cultivado para colheita de vagens e grãos verdes, sendo comum seu cultivo por pequenos e médios produtores fluminenses.

Tabela 1. Resultados da análise química do solo da área experimental. Seropédica (RJ), 2004

\begin{tabular}{|c|c|c|c|c|c|c|c|c|c|c|}
\hline Profundidade & $\mathrm{pH}$ & $\mathrm{Al}$ & $\mathrm{Ca}+\mathrm{Mg}$ & $\mathrm{Ca}$ & $\mathrm{Mg}$ & $\mathrm{P}$ & K & $\mathrm{C}$ & $\mathrm{MO}$ & $\mathrm{N}$ \\
\hline $\mathrm{cm}$ & em água & 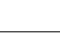 & $-\mathrm{cmol}$ & $n^{-3}-$ & 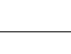 & \multicolumn{2}{|c|}{$-\mathrm{mg} \mathrm{dm}^{-3}-$} & \multicolumn{3}{|c|}{$\%$} \\
\hline $0-20$ & 5,2 & 0,0 & 4,6 & 3,1 & 1,5 & 29 & 76 & 0,60 & 1,03 & 0,0923 \\
\hline
\end{tabular}

O delineamento experimental utilizado foi em blocos casualizados, com cinco repetições. Os tratamentos constaram dos seguintes arranjos: a) monocultivo de mandioca; b) mandioca + milho; c) mandioca + caupi; e d) mandioca + milho + caupi. Cada parcela experimental foi composta por seis linhas de mandioca de 5,0 m de comprimento, sendo a área útil formada por quatro linhas centrais (Figura 2).

O plantio da mandioca foi realizado em 13 de setembro de 2004, utilizando-se manivas-semente de $15 \mathrm{~cm}$ de comprimento e 2,0 cm de diâmetro. Estas foram colocadas em sulcos não adubados, a $10 \mathrm{~cm}$ de profundidade, com espaçamento de 0,60 x 1,00 m (16.667 plantas ha $\left.{ }^{-1}\right)$. Os consortes foram semeados 49 dias após o plantio (DAP) da cultura principal, sendo o milho alternado em relação às entrelinhas da cultura principal, correspondendo ao espaçamento de $2,0 \times 0,5 \mathrm{~m}$ (20.000 plantas ha-1), com duas plantas por cova, adubadas com $100 \mathrm{~g}$ da mistura $(1: 1, \mathrm{v} / \mathrm{v})$ de cinzas de lenha e farinha de ossos $+500 \mathrm{~g}$ de esterco bovino curtido (Tabela 2). O caupi foi semeado em sulcos não adubados, na densidade de 12 sementes $\mathrm{m}^{-1}$, formando-se fileiras duplas espaçadas em $0,50 \mathrm{~m}$ entre si e dispostas nas entrelinhas alternadas da mandioca (120.000 plantas ha-1). O arranjo mandioca + milho + caupi foi desenvolvido de modo similar aos consórcios simples, assim, todas as entrelinhas da mandioca foram cultivadas.

Foram feitas adubações em cobertura no milho, aos 21 e 50 dias após a semeadura (DAS) com $200 \mathrm{~g}$ de "cama" de frango (Tabela 2). Durante a formação da espiga, realizaram-se três aplicações foliares com o produto comercial à base de Bacillus thuringiensis para o controle de lagartas.
Foram realizadas capinas 34 DAP da mandioca, apenas nas linhas cultivadas; aos 47 DAP, por ocasião da semeadura dos consortes; e aos 67 DAP, cobrindo toda a área experimental. O experimento foi irrigado por aspersão durante todo o ciclo do milho, quando constatada a ocorrência de deficiência hídrica.
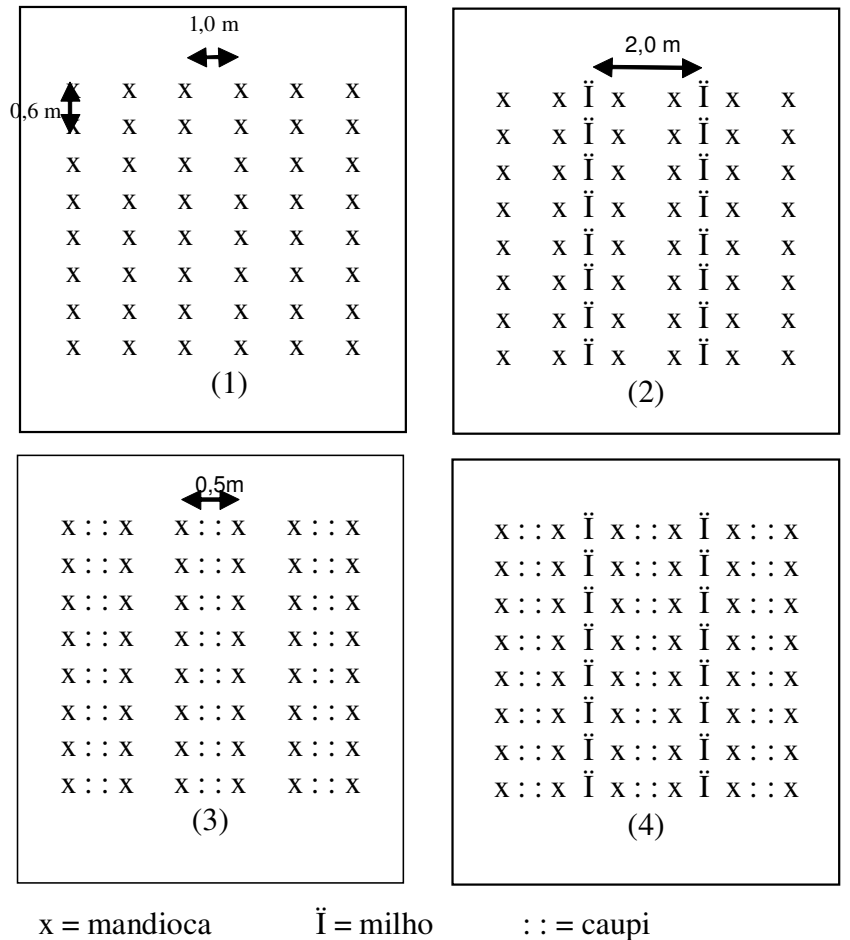

Figura 2. Arranjos espaciais, representando os tratamentos avaliados: (1) monocultivo de mandioca $(1,0 \times 0,60 \mathrm{~m}) ;(2)$ mandioca consorciada com milho; (3) mandioca consorciada com caupi; e (4) mandioca consorciada com milho e caupi. Seropédica-RJ, 2004. 
Tabela 2. Composição química dos insumos utilizados para adubação do milho. Seropédica (RJ), 2005

\begin{tabular}{lrrrrr}
\hline Insumos & $\mathrm{N}$ & $\mathrm{P}$ & $\mathrm{K}$ & $\mathrm{Ca}$ & $\mathrm{Mg}$ \\
\cline { 2 - 5 } & & & $\mathrm{g} \mathrm{kg}^{-1}$ & & \\
\cline { 2 - 6 } Esterco bovino & 22,96 & 4,55 & 20,50 & 47,07 & 11,25 \\
"Cama" de frango & 25,96 & 20,55 & 10,00 & 36,60 & 7,00 \\
Cinzas de lenha + farinha de ossos* & 10,37 & 35,81 & 82,85 & 310,38 & 18,75 \\
\hline
\end{tabular}

*(1:1, volume/volume).

Na colheita, foram avaliadas na área útil da parcela experimental, 24 plantas de mandioca $\left(14,4 \mathrm{~m}^{2}\right)$ colhidas aos 254 DAP; espigas de 32 plantas de milho $\left(16 \mathrm{~m}^{2}\right)$ colhidas 84 DAS (133 DAP da mandioca) e a biomassa de 24 plantas de caupi $\left(1,67 \mathrm{~m}^{2}\right)$, cortado no início da floração, aos 50 DAS (84 DAP da mandioca).

Foram avaliadas as seguintes características: a) mandioca - produção total e comercial de raízes; número, massa, diâmetro e comprimento médio de raízes comerciais; cozimento, produção da parte aérea e índice de colheita (produção de raízes/produção total de biomassa $\times 100$ ); b) milho - ciclo vegetativo, produção de espigas comerciais (número, comprimento, diâmetro e massa); c) caupi - massa de matéria verde e seca da parte aérea e composição de nutrientes. Os dados obtidos na área útil das parcelas experimentais foram convertidos para megagrama por hectare $\left(\mathrm{Mg} \mathrm{ha}^{-1}\right)$

Os resultados foram submetidos à análise de variância pelo teste $F(p=0,05)$. Os dados referentes às características avaliadas na cultura da mandioca foram comparados pelo teste de Tukey $(p=0,05)$ e aqueles referentes ao milho e ao caupi pelo teste $t$ Student $(p=0,05)$. Para análise estatística utilizouse o programa SAS v.6.11 (SAS INSTITUTE INC., 1996).

\section{RESULTADOS E DISCUSSÃO}

A mandioca produziu, em média, $63,44 \mathrm{Mg} \mathrm{ha}^{-}$ ${ }^{1}$ de massa fresca e $33,32 \mathrm{Mg} \mathrm{ha}^{-1}$ de raízes comerciais. Essa produtividade é considerada elevada quando comparada às lavouras comerciais do estado de São Paulo, onde a IAC 576-70 ocupa praticamente toda a área cultivada com essa cultura a qual tem a média estimada para o ano agrícola 2004/05 de $16 \mathrm{Mg}^{-{ }^{-1}}$ de mandioca de "mesa" (CASER et al., 2005). Apresentou, também, desempenho superior a outros resultados experimentais encontrados na literatura (Arias et al, 2005; Aguiar, 2003 e outros). Essa produtividade é ainda mais expressiva se considerarmos que as plantas foram colhidas com relativa precocidade, aproximadamente oito meses e ainda enfolhadas. Assim, a mandioca produzida em sistema orgânico, além de viável, apresentou desempenho favorável, quer nas condições de cultivo solteiro ou consorciada com milho, caupi, ou ambos consortes simultâneos. As condições férteis do solo e a irrigação suplementar favoreceram o desempenho da mandioca e das outras culturas, permitindo colheitas precoces, o que favorece o uso da terra e a renda do agricultor.

Tabela 3. Produtividade comercial, número de raízes por planta e massa, diâmetro e comprimento médio de raízes tuberosas de mandioca (cv. IAC 576-70), sob manejo orgânico, em monocultivo e em consórcios simultâneos com milho, caupi, e milho + caupi, aos 254 DAP. Seropédica (RJ), 2005

\begin{tabular}{|c|c|c|c|c|c|c|}
\hline Tratamentos & $\begin{array}{l}\text { Produtividade } \\
\text { comercial }\end{array}$ & $\begin{array}{c}\text { Raízes por } \\
\text { planta }\end{array}$ & $\begin{array}{l}\text { Massa } \\
\text { média da } \\
\text { raiz }\end{array}$ & $\begin{array}{l}\text { Diâmetro } \\
\text { médio da } \\
\text { raiz }\end{array}$ & $\begin{array}{c}\text { Comprimento } \\
\text { médio da } \\
\text { raiz }\end{array}$ & $\begin{array}{c}\text { Tempo } \\
\text { de cozimento }\end{array}$ \\
\hline & $\mathrm{Mg} \mathrm{ha}^{-1}$ & n..$^{\circ}$ & $\mathrm{g}$ & \multicolumn{2}{|c|}{$\mathrm{cm}$} & $\min$ \\
\hline Mandioca & $36,31 \mathrm{~A}$ & $6,47 \mathrm{~A}$ & $337 \mathrm{~A}$ & $5,64 \mathrm{~A}$ & $28,80 \mathrm{~A}$ & 15 \\
\hline Mandioca + milho & $28,58 \mathrm{~A}$ & $5,08 \mathrm{~A}$ & $338 \mathrm{~A}$ & $5,68 \mathrm{~A}$ & $25,80 \mathrm{~B}$ & 15 \\
\hline Mandioca + caupi & $30,54 \mathrm{~A}$ & $5,34 \mathrm{~A}$ & $346 \mathrm{~A}$ & $5,60 \mathrm{~A}$ & $27,80 \mathrm{~A}$ & 15 \\
\hline Mand.+ milho/caupi & $30,17 \mathrm{~A}$ & $5,33 \mathrm{~A}$ & $339 \mathrm{~A}$ & $5,82 \mathrm{~A}$ & $25,40 \mathrm{~B}$ & 15 \\
\hline $\mathrm{CV}(\%)$ & 13,84 & 13,36 & 8,54 & 2,18 & 2,81 & - \\
\hline DMS & 8,16 & 1,39 & 54,51 & 0,23 & 1,42 & - \\
\hline
\end{tabular}

Médias seguidas da mesma letra, nas colunas, não diferem entre si pelo teste de Tukey $(p \leq 0,05)$. 
Não foram detectadas diferenças significativas entre tratamentos para os valores de produtividade comercial, número de raízes por planta, peso e diâmetro basal médios das raízes (Tabela 3). Somente para comprimento da raiz houve diferença, sendo que as raízes colhidas do monocultivo e do consórcio com caupi apresentaram formato mais alongado, padrão plenamente satisfatório para o mercado in natura. Amostras de raízes comerciais, coletadas ao acaso nos diferentes tratamentos, não apresentaram qualquer tipo de deterioração até 48 horas após a colheita. O cozimento das raízes de todos os tratamentos foi rápido, por volta de 15 minutos (Tabela 3), sendo facilmente esmagadas por garfo até o "ponto de purê", o que segundo Normanha (1988), é indicativo de produto de excelente qualidade, comprovada pela apreciação sensorial.

A mandioca teve altas produções de massa de matéria verde de raízes e da parte aérea (Tabela 4), confirmando alto potencial produtivo em condições não estressantes. $\mathrm{O}$ cultivo solteiro teve o melhor desempenho com produção de $38,32 \mathrm{Mg}_{\text {ha }}{ }^{-1}$ de raízes e $71,76 \mathrm{Mg} \mathrm{ha}^{-1}$ de biomassa total. Em consórcio, a produção de raízes teve tendência a reduzir-se, principalmente mandioca + milho, mas sem magnitude suficiente para que fosse estatisticamente significativa (Tabela 4 ).

Tabela 4. Massa de matéria verde de raízes (MVr), da parte aérea (MVpa) e total (MVt) e índice de colheita (IC) da mandioca (cv. IAC 576-70), sob manejo orgânico, em monocultivo e em consórcios simultâneos com milho, caupi e milho + caupi, aos 254 DAP. Seropédica-RJ, 2005

\begin{tabular}{|c|c|c|c|c|}
\hline Tratamento & $\mathrm{MVr}$ & MVpa & $\mathrm{MVt}$ & IC \\
\hline & $x^{2}$ & $\mathrm{Mg} \mathrm{ha}^{-1}$ & & $\%$ \\
\hline Mandioca & $38,32 \mathrm{~A}$ & $33,44 \mathrm{~A}$ & $71,76 \mathrm{~A}$ & $53,5 \mathrm{~A}$ \\
\hline Mandioca + milho & $30,38 \mathrm{~A}$ & $28,54 \mathrm{~A}$ & $58,92 \mathrm{~B}$ & $51,4 \mathrm{~A}$ \\
\hline Mandioca + caupi & $32,20 \mathrm{~A}$ & $29,60 \mathrm{~A}$ & $61,80 \mathrm{AB}$ & $52,2 \mathrm{~A}$ \\
\hline Mandioca + milho/caupi & $32,38 \mathrm{~A}$ & $28,89 \mathrm{~A}$ & $61,27 \mathrm{AB}$ & $52,6 \mathrm{~A}$ \\
\hline $\mathrm{CV}(\%)$ & 13,57 & 9,80 & 9,31 & 7,42 \\
\hline DMS & 8,49 & 5,54 & 11,09 & 7,30 \\
\hline
\end{tabular}

Médias seguidas da mesma letra, nas colunas, não diferem entre si pelo teste de Tukey $(\mathrm{p} \leq 0,05)$.

A maior ação prejudicial foi provocada pelo milho na produção de matéria verde total de mandioca, que se reduziu em cerca de $18 \%$. Os demais arranjos não causaram prejuízos significativos à mandioca, embora em todos diminuíssem a produção total de massa fresca de raízes, da parte aérea e o índice de colheita (Tabela 4). Entretanto, Olasantan et al. (1996) registraram vantagens ecológicas do consórcio entre mandioca e milho em relação ao cultivo "solteiro", o que pode ser notado em função do aporte de biomassa e cobertura do solo.

O caupi não teve efeito prejudicial significativo à mandioca, e ainda reduziu o efeito negativo do milho no arranjo mandioca + milho + caupi na produção total de massa fresca de raízes. Também no município de Seropédica (RJ), a cultivar Saracura de mandioca, tradicional na região, com o manejo orgânico, porém em condições menos férteis e sem irrigação, produziu cerca de $29 \%$ mais raízes no consórcio mandioca + crotalária (Crotalaria juncea) do que no cultivo solteiro (LOPES, 2003; LOPEs et al., 2005). A leguminosa cultivada nas entrelinhas da mandioca recebeu três cortes durante o ciclo, sendo capinada aos 60 DAS, na floração. Foi obtida uma produção de $16,21 \mathrm{Mg} \mathrm{ha}^{-1}$ de raízes próprias para 'mesa' (Lopes et al., 2005), confirmando o efeito favorável das fabáceas (leguminosas).

O índice de colheita (IC), que caracteriza a relação entre a parte colhida (raízes) e a biomassa aérea da mandioca, ao redor de $52 \%$, não foi alterado pelos consórcios, sendo inferior ao esperado para a cultivar IAC 576-70, devido à colheita precoce, quando as plantas ainda estavam bastante enfolhadas. Esses resultados confirmam as observações feitas por KAWANO (1982) que, em condições favoráveis, pode ser obtida alta produtividade, mesmo com IC não muito alto, devido ao excesso de massa da parte aérea.

Com relação à cultura do milho, o embonecamento foi uniforme e iniciou-se aos 63 DAS. As adubações de cobertura estimularam o desenvolvimento das plantas, compensando o sombreamento inicial da mandioca, a qual teve crescimento além do esperado, provavelmente por causa da irrigação. As espigas foram colhidas aos $84 \mathrm{DAP}$, no ponto de milho verde e estádio fenológico: grãos leitosos. Imediatamente após a colheita, as plantas foram cortadas rente ao solo e distribuídas nas entrelinhas da mandioca, formando boa cobertura do solo. 
O número de espigas, massa média com ou sem palha (Tabela 5) e as dimensões (Tabela 6) não foram influenciadas pela presença do caupi, possivelmente porque não houve competição durante a sua formação e crescimento (MAGALHÃES e DuRÃEs, 2005). Nos consórcios, o milho produziu, em média, $82 \%$ de espigas aptas para o comércio hortícola, equivalendo a aproximadamente $18 \mathrm{mil}$ espigas ha ${ }^{-1}$ superando o valor de $70 \%$ obtido por Araújo e Almeida (2000) para a cv. Sol da Manhã ND ('BR-4158', atualmente cv. Eldorado) sob idêntico manejo orgânico, nas condições da Baixada Fluminense. Também, os valores de comprimento e diâmetro basal de 17,9 e $3,8 \mathrm{~cm}$ respectivamente, foram inferiores aos verificados no presente trabalho.

Tabela 5. Número de espigas verdes por hectare, rendimento comercial e massa média da espiga com e sem palhas, do cultivar Eldorado de milho, sob manejo orgânico, em consórcios simultâneos com mandioca e mandioca + caupi. Seropédica (RJ), 2005

\begin{tabular}{lcccr}
\hline Tratamento & Espigas verdes & Rendimento comercial & \multicolumn{2}{c}{ Massa média da espiga } \\
\cline { 2 - 5 } & n. ${ }^{\circ}$ espigas ha ${ }^{-1}$ & $\%$ & com palha & sem palha \\
Milho + mandioca & $17.500 \mathrm{~A}$ & $86 \mathrm{~A}$ & $272,73 \mathrm{~A}$ & $201,25 \mathrm{~A}$ \\
Milho + mandioca + caupi & $18.750 \mathrm{~A}$ & $78 \mathrm{~A}$ & $280,03 \mathrm{~A}$ & $196,21 \mathrm{~A}$ \\
\hline CV $(\%)$ & 16,83 & 15,43 & 9,37 & 9,02 \\
DMS & 4.563 & 18,92 & 38,72 & 26,81 \\
\hline
\end{tabular}

Médias seguidas da mesma letra, nas colunas, não diferem entre si pelo teste $t$ Student $(p \leq 0,05)$.

Tabela 6. Comprimento e diâmetro basal médios das espigas verdes (padrão comercial) da cv. Eldorado de milho, sob manejo orgânico, em consórcios simultâneos com mandioca e com mandioca+caupi. Seropédica (RJ), 2005

\begin{tabular}{lcc}
\hline Tratamento & Comprimento & Diâmetro basal \\
\cline { 2 - 3 } & \multicolumn{2}{c}{$\mathrm{cm}$} \\
Milho + mandioca & $19,57 \mathrm{~A}$ & $4,35 \mathrm{~A}$ \\
Milho + mandioca + caupi & $19,24 \mathrm{~A}$ & $4,43 \mathrm{~A}$ \\
\hline CV (\%) & 6,78 & 5,10 \\
DMS & 1,97 & 0,34 \\
\hline
\end{tabular}

Médias seguidas da mesma letra, nas colunas, não diferem entre si pelo teste t Student $(\mathrm{p} \leq 0,05)$.

O caupi cobriu totalmente o solo já a partir dos $20 \mathrm{DAP}$, sendo cortado aos $48 \mathrm{DAP}$, no estádio de florescimento e distribuído nas entrelinhas da mandioca. A produção de massa verde e seca da parte aérea, em média, foi, respectivamente, de 12 e 1,48 Mg $\mathrm{ha}^{-1}$, porém não houve diferenças significativas entre os consórcios testados (Tabela 7). A influência positiva sobre a produção de raízes da mandioca, embora não significativa, pode estar associada ao aporte de nitrogênio, via fixação biológica, e à decomposição da biomassa aérea do caupi após o corte. O nitrogênio e outros nutrientes liberados na decomposição provavelmente foram aproveitados pelas culturas em consórcio, ou seja, a mandioca e o milho, ou mobilizados no solo mediante ação da biota (HÖDTKE et al., 1997). Essa atividade de organismos decompositores da matéria orgânica seria acelerada pela oferta do nitrogênio da massa fresca do caupi, subsequente ao acamamento das plantas de milho, em função da alta relação $\mathrm{C} / \mathrm{N}$ desse material. Além disso, a cobertura morta reduz perdas de umidade na camada superficial do solo, assim como as variações térmicas (LAMAs, 2007).

Tabela 7. Massa de matéria verde (MVpa) e seca (MSpa) da parte aérea de caupi (cv. Mauá), sob manejo orgânico, em consórcios simultâneos com mandioca e mandioca + milho, aos 50DAP. Seropédica-RJ, 2005

\begin{tabular}{lcc}
\hline Tratamento & MVpa & MSpa \\
\hline Caupi + mandioca & \multicolumn{3}{c}{$\mathrm{Mg} \mathrm{ha}^{-1}$} \\
Caupi + mandioca + milho & $11,60 \mathrm{~A}$ & $1,49 \mathrm{~A}$ \\
CV $(\%)$ & 21,83 & $1,46 \mathrm{~A}$ \\
DMS & 3,91 & 23,93 \\
\hline
\end{tabular}

Médias seguidas da mesma letra, nas colunas, não diferem entre si pelo teste $t$ Student ( $\mathrm{p} \leq 0,05)$.

Os valores médios relativos ao acúmulo de biomassa aérea, por ocasião do florescimento do caupi, foram proporcionais àqueles registrados por Alvarenga et al. (1995) em monocultivo da leguminosa. Em Seropédica (RJ), Lopes (2003) analisou o consórcio simultâneo entre caupi (cultivar do grupo 
"fradinho") e mandioca (cv. Saracura), assinalando valores, também, comparáveis ao do presente estudo. Assim, com 200.000 plantas ha ${ }^{-1}$ cortadas na floração, este autor constatou $32,60 \mathrm{Mg} \mathrm{ha}^{-1}$ de massa verde da

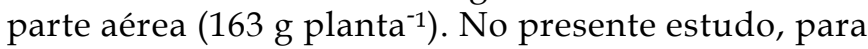
a população de 120.000 plantas, o caupi acumulou cerca de $100 \mathrm{~g}_{\text {planta }}{ }^{-1}$ de matéria fresca.

Os resultados das quantidades de nutrientes acumuladas na parte aérea do caupi estão relacionados na tabela 8 . Lopes (2003), no consórcio com mandioca aqui já referenciado, relatou acúmulo correspondente a, aproximadamente, $100 \mathrm{~kg}$ de $\mathrm{N}$ ha $^{-1}$ na parte aérea do caupi. Quanto a esta característica, novamente os dados são proporcionalmente comparáveis aos do presente estudo.

Em monocultivo, a mandioca não utiliza maximamente os fatores energia radiante, água e nutrientes, durante os três primeiros meses de seu ciclo vegetativo, devido ao lento desenvolvimento inicial da planta, possibilitando o consórcio com culturas de ciclo curto (DEvide, 2006).

Tabela 8. Acúmulo de cálcio, magnésio, fósforo, potássio, nitrogênio, matéria orgânica e carbono na parte aérea do caupi (cv. Mauá), sob manejo orgânico, em consórcios simultâneos com mandioca e mandioca + milho, aos 50 DAP. Seropédica-RJ, 2005

\begin{tabular}{lccccccc}
\hline Tratamento & $\mathrm{Ca}$ & $\mathrm{Mg}$ & $\mathrm{P}$ & $\mathrm{K}$ & $\mathrm{N}$ & $\mathrm{MO}$ & $\mathrm{C}$ \\
\cline { 2 - 7 } & & & & $\mathrm{kg} \mathrm{ha}^{-1}$ & & & \\
Caupi + mandioca & $8,24 \mathrm{~A}$ & $1,99 \mathrm{~A}$ & $2,00 \mathrm{~A}$ & $13,71 \mathrm{~A}$ & $44,65 \mathrm{~A}$ & $1278,4 \mathrm{~A}$ & $710,2 \mathrm{~A}$ \\
Caupi + mandioca+milho & $8,75 \mathrm{~A}$ & $2,06 \mathrm{~A}$ & $1,83 \mathrm{~A}$ & $16,58 \mathrm{~A}$ & $42,02 \mathrm{~A}$ & $1249,4 \mathrm{~A}$ & $694,1 \mathrm{~A}$ \\
\hline CV $(\%)$ & 46,52 & 44,98 & 37,50 & 48,76 & 25,03 & 24,35 & 24,35 \\
DMS & 5,91 & 1,36 & 1,07 & 11,04 & 16,23 & 460,29 & 255,71 \\
\hline
\end{tabular}

Médias seguidas da mesma letra, nas colunas, não diferem entre si pelo teste $t$ Student $(p \leq 0,05)$.

Os genótipos de mandioca com crescimento ereto (ramificação tardia) e vigor médio estabelecem menos competição por energia radiante em cultivos associados. A cultivar IAC 576-70 emite a primeira ramificação ocorrendo na metade da altura da planta e ramificação tricotômica em ângulo agudo (LoRENZI, 2003). Essas características favoreceram os tratos culturais e a consorciação com o milho e o caupi.

A conveniência do uso do consórcio triplo baseia-se no fato de que, além da colheita adicional das espigas de milho para direta comercialização, assegura-se, simultaneamente, a adubação verde da área cultivada. Tal procedimento torna-se estratégico para sistemas agroecológicos de produção, tendo em vista a necessidade do aporte sistemático de matéria orgânica ao solo, o que promove a redução de fertilizações com estercos, tortas, compostos e mesmo alguns fertilizantes minerais de baixa solubilidade.

Outros autores registraram efeitos de leguminosas sobre a produtividade da mandioca, quando em consórcio simultâneo. MAtTos et al. (1994a), por exemplo, obtiveram rendimento, em raízes comerciais, de $27,56 \mathrm{Mg} \mathrm{ha}^{-1}$ usando linhas duplas de plantio $(2,00 \times 0,60 \times 0,60 \mathrm{~m})$, em consórcio com o amendoim (Arachis hypogea), enquanto o monocultivo produziu 25,32 $\mathrm{Mg}^{-1}$ nesse mesmo espaçamento; em fileiras simples $(1,00 \times 0,60 \mathrm{~m})$, contudo, o consórcio reduziu a produtividade $\left(16,84 \mathrm{Mg} \mathrm{ha}^{-1}\right)$ quando comparado ao monocultivo $\left(19,99 \mathrm{Mg} \mathrm{ha}^{1}\right)$. Em consórcio simultâneo com a soja (Glycine max) para colheita de grãos, a mandioca proporcionou redução de produtividade, o que foi atribuído por MATTOs et al. (1994b) ao estresse hídrico ocorrido no período inicial de desenvolvimento das culturas. No espaçamento convencional de $1,00 \times 0,60 \mathrm{~m}$, a produção de raízes de mandioca no consórcio com a soja foi reduzida $\left(15,15 \mathrm{Mg} \mathrm{ha}^{-1}\right)$ em comparação ao cultivo "solteiro", no qual o rendimento chegou a $23,53 \mathrm{Mg}$ ha $^{1}$ no espaçamento em fileiras duplas $(2,00$ x 0,60 x 0,60 m), todavia essas diferenças não foram significativas (MATTOs et al., 1994a,b).

Nas condições estudadas, a curta duração do ciclo do caupi até o estádio de florescimento, o torna uma espécie promissora para consórcios simultâneos. Adubos verdes, quando semeados nas entrelinhas de culturas econômicas permitem a contínua exploração agrícola de determinada área, o que se reveste de interesse, sobretudo para pequenos estabelecimentos rurais, pelo potencial de melhor aproveitamento de fatores de produção, como energia radiante, água e nutrientes, além do fluxo de renda familiar. Entretanto, esse tipo de consórcio, na maioria dos casos, não é recomendável em situações de reduzida pluviosidade sem o recurso da irrigação (EsPíndolA et al., 1997). 
Para o cultivo consorciado de mandioca em fileiras simples, LoRENZI (2003) preconiza o espaçamento de 1,00 a 1,20 m entrelinhas e de 0,60 a $0,80 \mathrm{~m}$ entre plantas, intercalando a cultura consorte apenas em linhas alternadas com as de mandioca. No presente trabalho foi possível obter-se elevada produtividade de raízes comercias em consórcio com milho e caupi, com o máximo aproveitamento do solo. Os critérios adotados para o consórcio triplo, sem modificar o espaçamento da mandioca $(1,00 \times 0,60 \mathrm{~m})$, foram adequados para as condições experimentais, conferindo elevada produtividade de raízes, de espigas verdes de milho, o aporte de nutrientes e nitrogênio do caupi, benéficos ao agroecossistema e ao agricultor.

\section{CONCLUSÕES}

1. A mandioca de "mesa" IAC 576-70 cultivada em manejo orgânico na Baixada Fluminense, Região Metropolitana do Estado do Rio de Janeiro, com irrigação suplementar no estádio inicial do ciclo, proporcionou alta produtividade em colheita precoce (8 1/2 meses), além de excelente padrão comercial.

2. A inclusão do milho, cv. Eldorado, cultivado nas entrelinhas alternadas da mandioca, após a primeira capina, não interferiu na produção comercial de raízes. A colheita de espigas verdes com padrão de mercado significa potencial de renda adicional ao agricultor, com melhor aproveitamento dos recursos disponíveis, inclusive justificando a irrigação.

3. O cultivo simultâneo do caupi cv. Mauá, nos arranjos espacial e temporal adotados, não exerce influência negativa na produtividade da mandioca ou do milho e agrega $\mathrm{N}$ ao solo.

4. O consórcio triplo mandioca + milho + caupi é recomendável, nas condições do estudo, tendo por base a contribuição da fabácea - leguminosa - em termos de aporte de matéria orgânica e de nutrientes, além da cobertura do solo e do conseqüente potencial de controle à erosão.

\section{REFERÊNCIAS}

AGUIAR, E. B. Produção e qualidade de raízes de mandioca de mesa (Manihot esculenta Crantz) em diferentes densidades populacionais e épocas de colheita. 2003. 90p. Dissertação (Mestrado em Agricultura Tropical e Subtropical, Área de Concentração em Tecnologia de Produção Agrícola). Instituto Agronômico (IAC), Campinas.

ALMEIDA, D. L; GUERRA, J.G.M.; RIBEIRO, R.L.D. Sistema integrado de produção agroecológica: uma experiência de pesquisa em agricultura orgânica. Seropédica: Embrapa Agrobiologia, 2003. 37p. (Embrapa Agrobiologia. Documentos, 169)

ALVARENGA, R.C.; COSTA, L. M.; FILHO, W.M.; REGAZZI, W.M. Características de alguns adubos verdes de interesse para a conservação e recuperação de solos. Pesquisa Agropecuária Brasileira, Brasília, v.30, n.2, p.175185, 1995.

ANDRADE, W.E.B.; CAETANO, L.C.S.;FERREIRA, J.M. A cultura do aipim: perspectivas, tecnologias e viabilidade. Niterói: Pesagro-Rio, 1999. 26p. (Pesagro-Rio RIO. Documento, 48)

ARAÚJO, P. A.; ALMEIDA, D. L.. Avaliação do desempenho de cultivares de milho para a colheita de espigas verdes em sistema orgânico de produção. Seropédica: RECOPE - Rede de Agroecologia do Estado do Rio de Janeiro, FAPERJ/FINEP, p. 22-26, 2000. (Rede Agroecologia Rio, Relatório Trimestral novembro/1999 a fevereiro/2000)

ARIAS, E.R.A.; ARIAS, S.M.S.; MARTINS, C.S.; PEREIRA, F.A.R.; OTSUBO, A.A. Avaliação da produtividade, tempo de cozimento e padrão de massa cozida de oito cultivars de mandioca tipo mesa, em Campo Grande, MS. In: CONGRESSO BRASILEIRO DE MANDIOCA, 11., Campo Grande, MS, 2005. Anais... Campo Grande: Embrapa Agropecuária-Oeste, 2005. CD-ROM.

BEZERRA, J.A. A Hora da Arrancada. Revista Globo Rural, Rio de Janeiro, n. 221, p.10-17, 2004.

CASER, D.V.; CAMARGO, A.M.M.P.; GHOBRIL, C. N.; CAMARGO, F.P.; ÂNGELO, J. A.; GIANNOTTI, J.D.G.; OLIVETTI, M.P.A.; FRANCISCO, V.L.F.S. Previsões e estimativas das safras agrícolas do Estado de São Paulo, ano agrícola 2004/05. 2005. Informações Econômicas, São Paulo, v. 35, n. 6, jun. 2005.

DEVIDE, A.C.P. Sistema orgânico de produção de mandioca consorciada com milho e caupi. 2006. 85 p. Dissertação (Mestrado em Agronomia - Fitotecnia), Universidade Federal Rural do Rio de Janeiro, Seropédica.

ESPÍNDOLA, J.A.A;GUERRA, J.G.M.; ALMEIDA, D.L. Adubação verde: estratégias para uma agricultura sustentável. Seropédica: Embrapa Agrobiologia, 1997. 20p. (Embrapa-Centro Nacional de Pesquisa de Agrobiologia. Documentos, 42)

FAO - Food \& Agriculture Organization of the United Nations. Faostat. Disponível em: http://apps.fao.org/cgi-bin/nphdb.pl. Acesso em julho, 2005.

HÖDTKE, M.; ALMEIDA, D. L. de; KOPKE, U.; ALVES, B. J. R.; URQUIAGA, S.; UNKOVICH, M. Balanço de nitrogênio em diferentes sistemas de produção orgânica para milho e caupi. In: Congresso Brasileiro de Ciência do Solo, 25, 1997, Rio de janeiro. Anais... Rio de Janeiro: SBCS, 1997. Seção temática 4.1 CD-ROM.

IBGE - Instituto Brasileiro de Geografia e Estatística. Censo Agropecuário: 1995-1996. Disponível em www.sidra.ibge.gov.br/ bda. Acesso em: novembro/2005. 
INMET/PESAGRO-RIO. Dados agroclimáticos. Seropédica: Estação Experimental de Seropédica, 2005.

KAWANO, K. Mejoramiento genetico de yuca para productividad. In: DOMÍNGUEZ, C. E. (Ed.) Yuca: investigación, producción y utilización. Cali: PNUD \& CIAT, 1982. p. $91-112$.

LAMAS, F. M. Espécies para cobertura do solo e seus efeitos no algodoeiro. Revista Brasileira de Oleaginosas e Fibrosas, Campinas Grande, v.11, n.1, p. 55-63, 2007.

LOPES, C. A. Efeito do consórcio entre mandioca e leguminosas na população de plantas espontâneas. 2003.91p. Tese (Doutorado em Agronomia - Fitotecnia), Universidade Federal Rural do Rio de Janeiro, Seropédica.

LOPES, C. A.; POLIDORO, J. C.; ABBOUD, A. C. deS.; PEREIRA, M. B. Acumulação e exportação de nitrogênio, fósforo e potássio pela cultura da mandioca consorciada com leguminosas em sistema orgânico de produção. In: CONGRESSO BRASILEIRO DE MANDIOCA, 11., 2005, Campo Grande. Anais... Campo Grande: Embrapa AgropecuáriaOeste, 2005. CD-ROM.

LORENZI, J.O. Mandioca. 1.ed. Campinas: CATI Coordenadoria de Assistência Técnica Integral, 2003. 116p. (CATI. Boletim Técnico, 245)

LORENZI, J.O; VALLE, T.L. IAC 576 - 70. A variedade de mandioca de mesa mais cultivada no estado de São Paulo. Campinas: Instituto Agronômico, 2002. (Fôlder)

LORENZI, J.O.; VALLE, T.L.; MONTEIRO, D.A.; PERESIN, V.A.; KANTHACK, R.A.D. Variedades de mandioca para o Estado de São Paulo. Campinas: Instituto Agronômico, 1996. 23p. (Boletim Técnico, 162)

MACHADO, A.T. Milho Crioulo: conservação e uso da biodiversidade. AS-PTA Rede de Projetos e Tecnologias Alternativas, Rio de Janeiro, 1998. 110p.

MAGALHÃES, P.C.; DURÃES, F.O.M. Ecofisiologia. Embrapa Milho e Sorgo, site: http:/ / www.embrapa.cnpms.gov.br, 2005. (Sistema de Produção 1)

MATTOS, P.L.P.; SOUZA, A.S.; CALDAS, R.C. Cultivo da mandioca e amendoim em sistemas consorciado e monocultivo. Revista Brasileira de Mandioca, Cruz das Almas, v.13, n.1, p.29-45, 1994a.

MATTOS, P.L.P.; SOUZA, A.S.; CALDAS, R.C. Avaliação do cultivo da mandioca em fileiras duplas e simples consorciada com soja. Revista Brasileira de Mandioca, Cruz das Almas, v.13, n.1, p.47-59, 1994b.

MDA - MINISTÉRIO DO DESENVOLVIMENTO AGRÁRIO. Instituto Nacional de Colonização e Reforma Agrária. Novo retrato da agricultura familiar: o Brasil redescoberto. Brasília: MDA, 2005.

NORMANHA, E.S. O mau cozimento dos aipins: uma hipótese. O Agronômico, Campinas, v.40, n.1, p.13-14, 1988.
OLASANTAN, F.O.; EZUMAH, H. C.; LUCAS, E. O. Effects of intercropping with maize on the micro-environment, growth and yield of cassava. Agriculture, Ecosystems \& Environment, v.57, n.2-3, p.149-158, 1996.

SAS - STATISTICAL ANALYSIS SYSTEM. STAT, version 6.11. Cary: Sas Institute, 1996.

VALLE, T. L. Mandioca: dos índios à agroindústria. Revista ABAM - Associação Brasileira dos Produtores de Amido de Mandioca, Ano III, n.11, p.24-25, julho-setembro/2005. 